\title{
Metastatic Male Breast Cancer: A Retrospective Cohort Analysis
}

\author{
Robert Foerster $^{\mathrm{a}} \quad$ Lars Schroeder $^{\mathrm{b}} \quad$ Frank Foerster $^{\mathrm{c}, \mathrm{d}} \quad$ Volker Wulffe $^{\mathrm{B}} \quad$ Birgit Schubotz $^{f}$ \\ Dieter Baaske ${ }^{f, g} \quad$ Christian Rudlowski ${ }^{b}$ \\ a Department of Radiation Oncology, National Center for Tumor Diseases, University Hospital, Heidelberg, Germany \\ ${ }^{b}$ Department of Gynecology and Obstetrics, University Hospital, Center of Integrated Oncology (CIO) Bonn, Germany \\ ' Department of Economic Sciences, University of Applied Sciences, Zwickau, Germany \\ d Outpatient Department of Gynecologic Oncology, Poliklinik GmbH, Chemnitz, Germany \\ ${ }^{\text {e }}$ Cancer Register of Southwest Saxony, Zwickau, Germany \\ ${ }^{f}$ Cancer Register of Chemnitz, Chemnitz, Germany \\ ${ }^{9}$ Department of Radiation Oncology, Klinikum Chemnitz, Chemnitz, Germany
}

\section{Keywords}

Male breast cancer - Metastasis · Prognosis

\section{Summary}

Background: Metastasized male breast cancer (MMBC) is a rare disease. Given its low incidence, data regarding tumor biology, current treatment options, and survival rates are scarce. Patients and Methods: A chart review was performed of MMBC patients consecutively registered in regional cancer registries in Germany between 1995 and 2011. Tumor characteristics, treatment, and survival rates were documented and statistically evaluated. Results: 41 men with MMBC represented $25.6 \%$ of a total of 160 patients with MBC. 16 (39\%) patients showed primary metastases, and $25(61 \%)$ had recurrent metastases. Median survival from occurrence of metastasis was 32 months. Median overall survival (OS) was 68 months. $68.3 \%(n=28)$ of the cohort received systemic therapy favoring endocrine therapy ( $n=25$, $61.9 \%)$. Prolonged metastatic OS ( $p=0.02$ ) was observed in patients having had a systemic treatment. Metastatic patients having received endocrine treatment showed significantly prolonged survival rates. Furthermore, patients receiving palliative chemotherapy had a significant survival benefit compared to those in whom chemotherapy was omitted. Conclusion: Our results suggest that systemic treatment in the form of both palliative chemotherapy and endocrine therapy improves outcome of

R. Foerster and L. Schroeder contributed equally to this article and are listed in alphabetical order.
MMBC. Therefore, it seems reasonable that treatment of MMBC should be based on the guidelines for female breast cancer.

\section{Introduction}

Male breast cancer (MBC) is a rare disease accounting for approximately $1 \%$ of all malignancies in men $[1,2]$ and being the cause of less than $0.5 \%$ of all cancer deaths in men annually [3]. Equally to female breast cancer, the incidence of breast cancer in men has been increasing over the last decades. It is proposed that the incidence has increased about $26 \%$ over the past 25 years [4]. However, the low incidence makes prospective studies difficult, and the majority of available data are retrospective studies with relatively small numbers of patients [5]. Today, most treatment recommendations for $\mathrm{MBC}$ are therefore derived from well-studied female breast cancer trials. However, in the last years, efforts have increased to reveal the nature of $\mathrm{MBC}$ and the differences to its female counterpart [6-8]. Although the information on $\mathrm{MBC}$ is steadily increasing, there is still a lack of knowledge surrounding metastatic MBC (MMBC). It is of specific interest to determine whether treatment of MMBC could improve survival, and whether the implementation of new treatment options would be as successful as recently demonstrated for the female counterpart [9]. The aim of this retrospective evaluation is to identify MMBC patients within a well-defined time period and population, and to examine clinical features and outcomes in this particular subset of MMBC patients.

\section{KARGER \\ Fax +497614520714 \\ Information@Karger.com}

www.karger.com
(C) 2014 S. Karger GmbH, Freiburg

1661-3791/14/0094-0267\$39.50/0

Accessible online at:

www.karger.com/brc
Christian Rudlowski M.D.

Department of Gynecology and Obstetrics

University Hospital Bonn

Sigmund-Freud-Str. 25, 53125 Bonn, Germany

rudlowski@t-online.de 


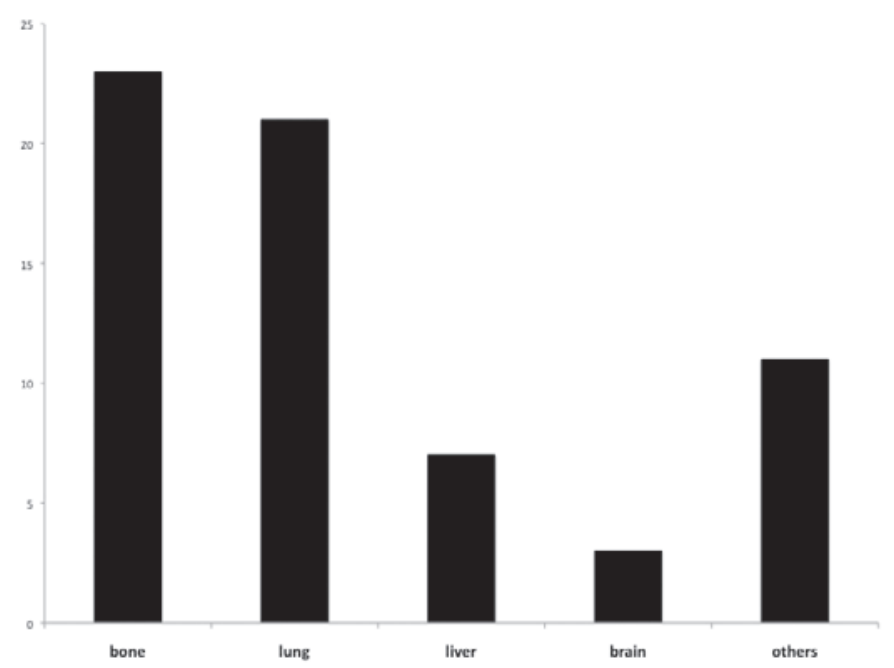

Fig. 1. Frequency of metastatic disease sorted by sites of occurrence. If more than 1 site was affected by metastatic disease in 1 patient, multiple notations were possible.

\section{Patients and Methods}

MMBC patients who were treated and registered in the administrative district of Chemnitz in the State of Saxony, Germany, were retrospectively analyzed within this retrospective cohort analysis. These men represent all metastatic cases among a total of 160 male patients consecutively diagnosed with MBC between 1995 and 2011 in this area which has approximately 1.5 million inhabitants [7]. Data was collected by the 2 regional cancer registries of the district of Saxony, located in the cities of Chemnitz and Zwickau.

Information was collected for items such as age, histology, TNM and UICC status, grading, date and site of metastasis, and accomplished treatments, as well as date of primary and secondary diagnosis and death. Detailed information was gathered regarding receptor status (estrogen, progesterone, HER2) as well as chemotherapy, endocrine therapy, and radiotherapy in both the adjuvant and the palliative setting. The receptor status was determined by immunohistochemistry; fluorescence in-situ hybridization was documented for HER2 if available.

All patients were diagnosed with MMBC by radiological imaging and/ or tumor biopsy. For these patients, tissue samples of the metastases were taken to confirm the diagnosis by immunohistochemistry.

Disease-free survival (DFS), overall survival (OS), and metastatic overall survival (MOS) estimations were calculated according to the logrank test and Kaplan-Meier method. DFS was calculated as the date of first diagnosis of MBC until the diagnosis of metastatic disease. OS was considered to be the time from first development of distant metastasis until death from any cause. MOS was considered as time from diagnosis of metastatic disease until death. A p value $\leq 0.05$ was considered to be statistically significant. A statistical analysis was performed using SPSS for Windows 21.0 software package (IBM Corp., Armonk, NY, USA).

\section{Results}

Of a total of $160 \mathrm{MBC}$ patients in this cohort, 41 (25.6\%) men had metastatic disease. $16(39 \%)$ patients presented with primary and 25 (61\%) with secondary metastases (recurrence). The average age at first diagnosis was 65.5 years (range 43-81 years). Various sites of metastasis were found (fig. 1) with pre-

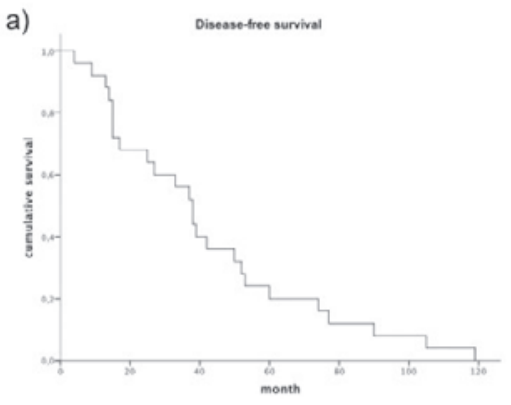

b)

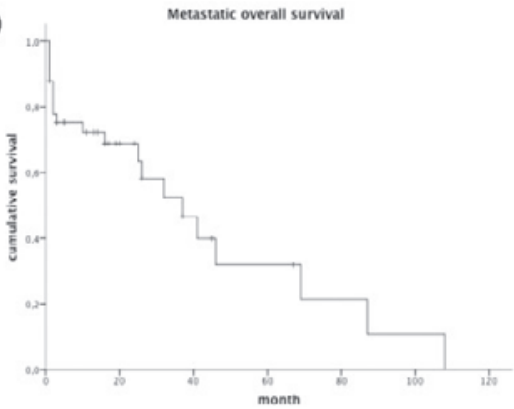

Fig. 2. a Diseasefree survival,

b metastatic overall survival, and c overall survival of the study group.

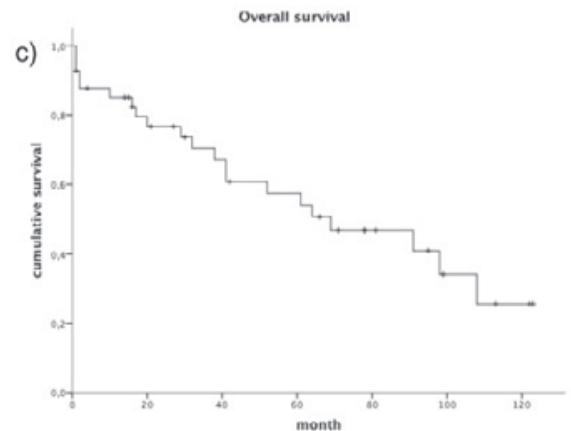

dominant bone $(\mathrm{n}=23)$ and lung $(\mathrm{n}=21)$ manifestations. Median DFS was 36 month (fig. 2 a). Median survival from the occurrence of metastasis was 32 months (fig. 2 b). 5-year OS was estimated to be $21.8 \%$ after metastasis occurred. Median OS from the time of primary diagnosis was 68 month (fig. 2 c). MOS was not observed to differ between patients with primary metastatic disease and those with secondary metastasis.

Tables 1 and 2 present the tumor characteristics and treatment modalities of the entire group. $81.5 \%(n=32)$ showed initial tumor stages $\geq$ II according to the UICC classification, and $56.8 \%(\mathrm{n}=21)$ had lymph node-positive disease. $97.3 \%$ had a histological grade of $2(\mathrm{n}=22,59.2 \%)$ or $3(\mathrm{n}=14$, $37.8 \%$ ). A positive hormone receptor status was found in $73.2 \%(\mathrm{n}=30)$ of all cases and in $90.2 \%$ of tumors in which the hormone receptor status was determined. In $12.2 \%(\mathrm{n}=5)$ the receptor status was unknown. The estrogen receptor was positive in $70.7 \%(n=29)$, and the progesterone receptor was positive in $63.4 \%(\mathrm{n}=26)$ of the entire study group. $12.2 \%(\mathrm{n}$ $=5)$ were positive for HER2, and $9.8 \%(n=4)$ were so-called 
Table 1. Patients characteristics and survival $(\mathrm{n}=41)$

\begin{tabular}{|c|c|c|c|c|c|}
\hline & & $\begin{array}{l}\text { Median OS, } \\
\text { month }\end{array}$ & $\mathrm{p}$ & $\begin{array}{l}\text { Median TTP } \\
\text { month }\end{array}$ & $\mathrm{p}$ \\
\hline \multirow{2}{*}{$\begin{array}{l}\text { Age at primary diagnosis, median (range), } \\
\text { years }\end{array}$} & $65.5(43-81)$ & & & & \\
\hline & Patients, n (\%) & & & & \\
\hline Age $<$ median & 20 & 95 & n.s. & 46 & 0.025 \\
\hline Age $\geq$ median & 21 & 61 & & 25 & \\
\hline \multicolumn{6}{|l|}{ Initial disease stage } \\
\hline I & $8(19.5)$ & 95 & 0.003 & 46 & n.s. \\
\hline II & $12(29.3)$ & 66 & & 26 & \\
\hline III & $5(12.2)$ & 61 & & 16 & \\
\hline IV & $15(39.0)$ & 61 & & 16 & \\
\hline \multicolumn{6}{|l|}{ Primary nodal stage } \\
\hline pN0 & $16(43.2)$ & 69 & n.s. & 37 & n.s. \\
\hline $\mathrm{pN}+$ & $21(56.8)$ & 41 & & 25 & \\
\hline \multicolumn{6}{|l|}{ Grading } \\
\hline 1 & $1(2.7)$ & 95 & n.s. & 19 & n.s. \\
\hline 2 & $22(59.5)$ & 66 & & 37 & \\
\hline 3 & $14(37.8)$ & 64 & & 26 & \\
\hline \multicolumn{6}{|l|}{ Hormone receptor status } \\
\hline Positive & $30(73.2)$ & 71 & 0.01 & 37 & 0.001 \\
\hline Negative & $5(12.2)$ & 17 & & 1 & \\
\hline Unknown & $6(14.6)$ & 20 & & 2 & \\
\hline \multicolumn{6}{|l|}{ HER-2 status } \\
\hline Negative & $25(83.3)$ & 66 & n.s. & 37 & n.s. \\
\hline Positive & $5(16.7)$ & 16 & & 41 & \\
\hline \multicolumn{6}{|l|}{ Metastasis } \\
\hline Primary & $16(39.0)$ & 16 & 0.001 & 26 & n.s. \\
\hline Secondary & $25(61.0)$ & 95 & & 20 & \\
\hline Single & $22(53.6)$ & 71 & n.s. & 26 & n.s. \\
\hline Multiple & $19(46.4)$ & 38 & & 25 & \\
\hline \multicolumn{6}{|l|}{ Dominant site of disease recurrence } \\
\hline Lung & $21(51.2)$ & 27 & n.s. & 26 & n.s. \\
\hline Bone & $23(56.1)$ & 41 & & 24 & \\
\hline Liver & $7(17.1)$ & 23 & & 32 & \\
\hline
\end{tabular}

triple negatives. Regarding OS, only patients with an initial tumor stage I or primary positive hormone receptors showed a significant survival benefit (table 1). MOS was significantly higher for younger patients and also patients with a positive hormone receptor status. However, triple-negative patients had a significantly reduced MOS ( $\mathrm{p}=0.03)$.

A total of $46.3 \%(n=19)$ of the patients received adjuvant systemic therapy, and $43.9 \%(\mathrm{n}=18)$ adjuvant radiotherapy. Adjuvant chemotherapy was administered to $26.8 \%(\mathrm{n}=11)$ of patients, consisting of taxanes, anthracyclines, or CMF (cyclophosphamide, methotrexate, 5-fluorouracil). 34.1\% ( $\mathrm{n}=$ 14) of the patients received adjuvant hormone therapy with tamoxifen or aromatase inhibitors (AI). 1 (4.6\%) patient received trastuzumab additionally to therapy with taxanes and tamoxifen (table 2).

A total of $68.3 \%(n=28)$ of the cohort (table 2$)$ received systemic palliative therapy (primary metastases $73.3 \%$; sec- ondary metastases $65.4 \%$ ), favoring endocrine therapy ( $\mathrm{n}=$ 25, 61.9\%). Prolonged MOS ( $\mathrm{p}=0.02$ ) (fig. 3 a) was observed in patients in whom a palliative systemic treatment was administered. Chemotherapy was administered in 17 (41.5\%) patients as first-line metastatic treatment, 5 (12.2\%) patients received chemotherapy as second-line therapy, and in 1 case a third-line chemotherapy was administered. The following agents were used for palliative chemotherapy: taxane/anthracycline combinations $(\mathrm{n}=10,24.4 \%)$, taxanes $(\mathrm{n}=3,7.3 \%)$, pegylated liposomal doxorubicin $(n=4,9.8 \%)$, vinorelbine ( $\mathrm{n}$ $=3,7.3 \%$ ) gemcitabine $(\mathrm{n}=2,4.9 \%)$, and CMF in 1 case. Bisphosphonates were used for patients with bone metastases in $17(73.9 \%)$ cases. Palliative radiotherapy was administered in $14(34.1 \%)$ patients. Survival analysis revealed that patients with palliative chemotherapy had a significant survival benefit compared to those in whom a chemotherapeutic treatment was omitted (fig. 3 b). 
Table 2. Treatment modalities of the study group

\begin{tabular}{lr} 
Adjuvant treatment & \\
Total & 19 \\
Chemotherapy & 11 \\
CMF & 4 \\
Anthracyclines & 4 \\
Taxanes & 2 \\
Taxane/trastuzumab & 1 \\
Endocrine therapy & 14 \\
Tamoxifen & 13 \\
Aromatase inhibitors & 1 \\
Palliative treatment & \\
Total & 28 \\
Chemotherapy & 17 \\
Anthracyclines/taxanes & 10 \\
Taxanes & 3 \\
Vinorelbine & 3 \\
Pegylated liposomal doxorubicin & 4 \\
Gemcitabine & 2 \\
CMF & 17 \\
Endocrine therapy & 25 \\
Tamoxifen & 12 \\
Aromatase inhibitors & 15 \\
GnRH + aromatase inhibitors & 4 \\
Fulvestrant & 2 \\
Pisphosphonates & 14 \\
\hline
\end{tabular}

$\mathrm{CMF}=$ Cyclophosphamide, methotrexate, 5-fluorouracil; GnRH = gonadotropin-releasing hormone.

Patients treated with antihormonal therapy received only tamoxifen in $12(29.2 \%)$ cases or AI in 15 (36.6\%) cases, whereas $4(9.8 \%)$ patients received gonadotropin-releasing hormone $(\mathrm{GnRH})$ analogues in combination with AI. Fulvestrant was given in $2(4.9 \%)$ cases. Metastatic hormone receptor-positive patients having received endocrine treatment showed a significant survival benefit compared to those without endocrine therapy (fig. $3 \mathrm{c}$ ).

\section{Discussion}

To the best of our knowledge, there are no prospective studies or treatment guidelines on MMBC [5]. Therefore, treatment recommendations for this specific situation are derived from female breast cancer guidelines or single-institution experiences. In order to expand the data available for $\mathrm{MMBC}$, and given the low prevalence of the disease, data collections were carried out by various institutions and cancer centers. In case reports and small retrospective studies, the successful use of chemotherapy [10-13] and hormonal treatment [14-19] in MMBC is reported. However, no data is available demonstrating an OS benefit for systemic treatment of MMBC.

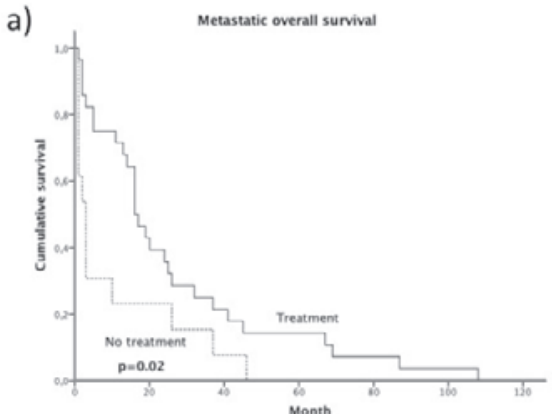

b)

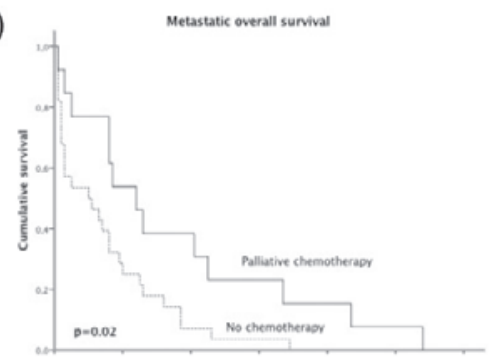

C)

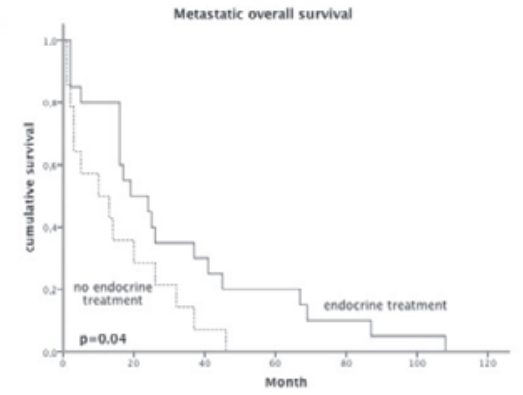

Fig. 3. Metastatic overall survival according to a palliative treatment, b chemotherapy treatment, and c endocrine treatment. etastatic patients in our analysis were diagnosed and treated at a variety of different institutions but registered consecutively in 2 regional tumor centers. Our retrospective cohort of $41 \mathrm{MMBC}$ patients revealed that systemic treatment conferred a significant survival benefit. Our data demonstrate a survival benefit for both palliative endocrine therapy and chemotherapy. This is of particular value due to the consideration that a significant number $(31 \%)$ of MMBC patients in our cohort received no palliative systemic treatment including palliative chemotherapy (68\%) and endocrine treatment (41\%) despite a positive hormonal status. Because of its retrospective character, these data on a small subset of patients cannot determine the exact clinical significance of systemic treatment in MMBC. Indications for palliative therapy and the type of treatment were individually and heterogeneously determined and not always in oncological centers. Therefore, our conclusions have to be viewed with caution. Nevertheless, our study strongly supports best possible treatment of MMBC.

Our patient group is characterized by a median MOS of 37 months, and statistical 5-year OS was calculated to be $21.7 \%$. This is well below values published by Giordano et al. [9] for 
women with metastatic disease diagnosed in between 1995 and 2000, demonstrating a median MOS of 58 months and a 5 -year MOS of $44 \%$. However, when comparing our results to those of women initially diagnosed between 1990 and 1994, similar values can be found (MOS 27 months, 5-year OS $29 \%$ ). This could be explained basically by the underpowered palliative treatment of MMBC documented in our cohort. For female breast cancer, Giordano et al. [9] found an improved OS for female patients by establishing a variety of new treatment options characterized by new substances and combinations. It is assumed that treatment of MMBC significantly improves survival.

In our patients group, effectiveness of endocrine therapy and chemotherapy was demonstrated. No subgroup analysis regarding the kind of endocrine treatment was carried out due to the small number of patients. Furthermore, a variety of different chemotherapy regimens were used in our cohort. Therefore, we cannot estimate which cytotoxic treatment is the best for MMBC as no sufficient data are available for this specific situation.

Due to the lack of guidelines and clinical studies, the treatment approach for MMBC should be similar to that in female patients. Based on the extremely high number of hormone receptor-positive male patients, endocrine therapy is the preferred treatment option even in the metastatic setting. However, it remains unclear which regimen should be selected. Tamoxifen is considered to be the first choice in the adjuvant setting [11]. However, no evidence exists whether AI should be given alone or combined with GnRH [19]. In addition, fulvestrant is reported in single case reports to be effective in MMBC [16]. Treatment strategies for the use of chemotherapy should be based on existing female treatment guidelines for metastatic breast cancer including trastuzumab for HER2-positive patients [20, 21]. Male patients presenting with bone metastasis should be treated with antiresorptive agents to prevent skeletal events and tumor progression. In the absence of any clinical data, the application of novel therapeutic regimens should be limited to more advanced MMBC based on female guidelines. Our study shows evidence that there is a strong need to collect data on MMBC, and supports efforts being made to treat these specific patients in breast cancer centers.

\section{Acknowledgement}

This work was supported by the German Cancer Foundation (project number 70-3157).

\section{Disclosure Statement}

We do not have any financial conflict of interest related to this publication

\section{References}

1 Chavez-Macgregor M, Clarke CA, Lichtensztajn D, Hortobagyi GN, Giordano SH: Male breast cancer according to tumor subtype and race: a population-based study. Cancer 2013;119:1611-1617.

2 Anderson WF, Jatoi I, Tse J, Rosenberg PS: Male breast cancer: a population-based comparison with female breast cancer. J Clin Oncol 2010;28:232-239.

3 Siegel R, Ward E, Brawley O, Jemal A: Cancer statistics, 2011: the impact of eliminating socioeconomic and racial disparities on premature cancer deaths. CA Cancer J Clin 2011;61:212-236.

4 Giordano SH, Cohen DS, Buzdar AU, Perkins G, Hortobagyi GN: Breast carcinoma in men: a population-based study. Cancer 2004;101:51-57.

5 Korde LA, Zujewski JA, Kamin L, Giordano S, Domchek S, Anderson WF, Bartlett JM, Gelmon K, Nahleh Z, Bergh J, Cutuli B, Pruneri G, McCaskillStevens W, Gralow J, Hortobagyi G, Cardoso F: Multidisciplinary meeting on male breast cancer: summary and research recommendations. J Clin Oncol 2010;28:2114-2122.

6 Anderson WF, Althuis MD, Brinton LA, Devesa SS: Is male breast cancer similar or different than female breast cancer? Breast Cancer Res Treat 2004;83:77-86.

7 Foerster R, Foerster FG, Wulff V, Schubotz B, Baaske D, Wolfgarten M, Kuhn WC, Rudlowski C: Matched-pair analysis of patients with female and male breast cancer: a comparative analysis. BMC Cancer 2011;11:335.
8 Cutuli B, Le-Nir CC, Serin D, Kirova Y, Gaci Z, Lemanski C, De Lafontan B, Zoubir M, Maingon $\mathrm{P}$, Mignotte H, de Lara CT, Edeline J, PenaultLlorca F, Romestaing P, Delva C, Comet B, Belkacemi Y: Male breast cancer. Evolution of treatment and prognostic factors. Analysis of 489 cases. Crit Rev Oncol Hematol 2010;73:246-254.

$\checkmark 9$ Giordano SH, Buzdar AU, Smith TL, Kau SW, Yang Y, Hortobagyi GN: Is breast cancer survival improving? Cancer 2004;100:44-52.

10 Lopez M, Di Lauro L, Papaldo P, Lazzaro B Chemotherapy in metastatic male breast cancer. Oncology 1985;42:205-209.

11 Giordano SH, Perkins GH, Broglio K, Garcia SG, Middleton LP, Buzdar AU, Hortobagyi GN: Adjuvant systemic therapy for male breast carcinoma. Cancer 2005;104:2359-2364.

12 Gennari R, Curigliano G, Jereczek-Fossa BA, Zurrida S, Renne G, Intra M, Galimberti V, Luini A, Orecchia R, Viale G, Goldhrisch A, Veronesi $\mathrm{U}$ : Male breast cancer: a special therapeutic problem. Anything new? (Review). Int J Oncol 2004; 24:663-670.

13 Walshe JM, Berman AW, Vatas U, Steinberg SM, Anderson WF, Lippman ME, Swain SM: A prospective study of adjuvant CMF in males with node positive breast cancer: 20-year follow-up. Breast Cancer Res Treat 2007;103:177-183.

14 Kantarjian H, Yap HY, Hortobagyi G, Buzdar A, Blumenschein G: Hormonal therapy for metastatic male breast cancer. Arch Intern Med 1983;143:237240.
5 Agrawal A, Ayantunde AA, Rampaul R, Robertson JF: Male breast cancer: a review of clinical management. Breast Cancer Res Treat 2007;103:11-21.

16 Agrawal A, Cheung KL, Robertson JF: Fulvestrant in advanced male breast cancer. Breast Cancer Res Treat 2007;101:123.

17 Patterson JS, Battersby LA, Bach BK: Use of tamoxifen in advanced male breast cancer. Cancer Treat Rep 1980;64:801-804.

18 Eggemann H, Ignatov A, Smith BJ, Altmann U, von Minckwitz G, Rohl FW, Jahn M, Costa SD: Adjuvant therapy with tamoxifen compared to aromatase inhibitors for 257 male breast cancer patients. Breast Cancer Res Treat 2013;137:465-470.

19 Zagouri F, Sergentanis TN, Koutoulidis V, Sparber C, Steger GG, Dubsky P, Zografos GC, Psaltopoulou T, Gnant M, Dimopoulos MA, Bartsch R: Aromatase inhibitors with or without gonadotropin-releasing hormone analogue in metastatic male breast cancer: a case series. Br J Cancer 2013; 108:2259-2263.

20 Rudlowski C, Friedrichs N, Faridi A, Fuzesi L, Moll R, Bastert G, Rath W, Buttner R: Her-2/neu gene amplification and protein expression in primary male breast cancer. Breast Cancer Res Treat 2004;84:215-223.

-21 Rudlowski C, Rath W, Becker AJ, Wiestler OD, Buttner R: Trastuzumab and breast cancer. N Engl J Med 2001;345:997-998. 